\title{
ANÁLISE DA VIABILIDADE ECONÔMICO-FINANCEIRA DE SISTEMAS DE DISPOSIÇÃO FINAL DE LODO DE ESGOTO
}

\author{
Júlia Vale D'Avila* \\ Marcela Cassin Chaves** \\ Fabiana Soares dos Santos*** \\ Afonso Aurelio de Carvalho Peres****
}

RESUMO: Objetivou-se analisar financeiramente cenários de sistemas para disposição final de lodo de esgoto doméstico. Os cenários foram: Estação de Tratamento que destina os resíduos sólidos produzidos para aterro sanitário e Estação de Tratamento que beneficia o lodo de esgoto, por meio do processo de compostagem para a produção de adubo, destinando outros resíduos sólidos ao aterro sanitário. As informações referentes ao inventário, infraestrutura, mão de obra, custos de manutenção e licenciamentos necessários para o funcionamento foram obtidos em uma Estação de Tratamento com capacidade média de tratamento de $3.356 \mathrm{~m}^{3}$ de esgoto por dia. $\mathrm{Na}$ análise de viabilidade financeira foram utilizados os indicadores econômicos, valor presente líquido e taxa interna de retorno. Realizaram-se as análises de sensibilidade e risco para identificar os itens de maior impacto negativo, bem como o risco financeiro, diante das oscilações de preços simuladas no mercado, por meio do método de Monte Carlo. A Estação que beneficia o lodo de esgoto para produção de adubo orgânico foi aquela que apresentou maior atratividade para investimento, apresentando uma rentabilidade de 61,6\% ao ano.

PALAVRAS-CHAVE: Análise de risco; Análise de sensibilidade; ETE; TIR; VPL.

\section{ECONOMIC AND FINANCIAL FEASIBILIT Y OF FINAL DISPOSAL SYSTEM OF SEWAGE SLUDGE}

ABSTRACT: Financial scenario systems on the final disposal of domestic sewage sludge are analyzed. Scenarios comprised Treatment Station, which disposes of solid residues produced for sanitary landfill, and Treatment Station that treats sewage

\footnotetext{
Mestre em Tecnologia Ambiental também pela Universidade Federal Fluminense, Brasil.

** Universidade Federal Fluminense. Mestrado em Tecnologia Ambiental, Brasil.

*** Universidade Federal Fluminense. Departamento de Engenharia de Agronegócios. Pós-Graduação em Tecnologia Ambiental. Brasil.

**** Universidade Federal Fluminense. Departamento de Engenharia de Agronegócios. Pós-Graduação em Tecnologia Ambiental. Brasil. E-mail: afonsoaurelio@id.uff.br
} 
sludge through a composting process for the production of fertilizers and the disposal of other solid wastes in the sanitary landfill. Data on inventory, infrastructure, labor, maintenance costs and warrants for functioning were obtained for the Treatment Station, with mean capacity of 3,356 m3 sludge/day. Economic indicators, net rate and internal return rate were used to analyze financial viability. Sensitiveness and risk analyses were performed to identify the items with the highest negative impact rates, coupled to financial risk, in the wake of market's simulated prices, by the Monte Carlo method. The station for the improvement of sewage sludge for the production of organic fertilizers had the best chance of receiving investments, with a $61.6 \%$ profit/year.

KEY WORDS: Risk analysis; Sensitivity analysis; ETE; TIR; VPL.

\section{INTRODUÇÃO}

O lodo de esgoto pode ser definido como um resíduo semi-sólido, pastoso e de natureza predominantemente orgânica, que tem um alto potencial de poluição e que quando não disposto corretamente acaba por anular parcialmente os benefícios de coleta e tratamento de efluentes (BETTIOL; CAMARGO, 2006). Atualmente, a maior parte do lodo de esgoto produzido em uma Estação de Tratamento de Esgoto (ETE) possui como destino final a sua disposição em aterros sanitários, gerando gastos para o empreendimento que pode representar até $50 \%$ do custo operacional de uma ETE (LOBO et al., 2015).

Considerando que o lodo de esgoto constituiu uma fonte de matéria orgânica e vários nutrientes, o seu uso agrícola é uma alternativa prevista na legislação brasileira, pela Resolução CONAMA 375/2006 (BRASIL, 2006), sendo uma forma de reintegrar o resíduo ao processo produtivo, podendo resultar em benefício social, ambiental e econômico de disposição final.

Diversos trabalhos vêm mostrando a viabilidade de utilização do lodo de esgoto para uso na agricultura (LEMAINSKI; SILVA, 2006; QUINTANA; CARMO; MELO, 2008; OLIVEIRA et al., 2008; LOBO et al., 2012; GOMES et al., 2013; LOBO et al., 2013) e na composição de substratos para produção de mudas de espécies florestais (GOMES et al., 2013; SANTOS et al., 2014; TRIGUEIRO; GUERRINI, 2014) sendo, 
em alguns casos, os seus benefícios superiores a adubação mineral recomendada para a cultura (SILVA et al., 2001; LOBO; GRASSI FILHO; BULL, 2012; LOBO et al., 2013). Sendo assim, a utilização agrícola do lodo de esgoto pode ser uma alternativa para reduzir os custos de produção devido aos nutrientes presentes em sua composição físico-química, além de reduzir os impactos ambientais de seu descarte.

No entanto o lodo de esgoto, dependendo da sua composição, pode representar uma fonte potencial de risco à saúde pública e ao meio ambiente, pois pode conter substâncias orgânicas, inorgânicas e agentes patogênicos em concentrações acima dos limites estabelecidos. Diante disso, a Resolução CONAMA no 375/2006 (BRASIL, 2006) define os limites máximos de contaminantes que podem estar presentes, além de critérios e procedimentos para uso agrícola do lodo de esgoto.

Como os agentes patogênicos são um dos principais contaminantes de lodo de esgoto doméstico, a legislação recomenda diversos processos para redução desses agentes presentes no lodo, entre eles a compostagem, que consiste em um processo de transformação biológica de materiais orgânicos em fertilizantes orgânicos utilizáveis na agricultura (DORES-SILVA; LANDGRAF; REZENDE, 2013).

Para se conhecer bem um sistema de tratamento de esgoto, é necessário conhecer, dentre outras coisas, o seu custo de produção e a viabilidade financeira do empreendimento. Diversos fatores influenciam nos custos de produção, por isso a determinação do mesmo é uma tarefa bastante complexa e demorada, pois envolve um grande número de cálculos, levantamentos, informações e requer muita atenção na realização da análise de viabilidade.

O conhecimento dos custos de produção permite ao empresário analisar economicamente a atividade e é por meio dessa análise que o investidor passa a conhecer com detalhes e a utilizar, de maneira inteligente e econômica, os fatores de produção. A partir daí, localiza-se os pontos de estrangulamento para depois concentrar esforços gerenciais e tecnológicos, para obter sucesso na sua atividade e atingir os seus objetivos, maximizando os lucros ou minimizando os custos de produção (LOPES; CARVALHO, 2001).

A análise financeira é um processo pelo qual o investidor passa a conhecer os resultados obtidos, em termos monetários, de cada fator integrante do investimento. É por meio de resultados econômicos que o investidor pode tomar conscien- 
temente suas decisões (LOPES; CARVALHO, 2001).

Objetivou-se, com o trabalho, avaliar a viabilidade financeira de diferentes formas de destinação do lodo de esgoto produzido em uma Estação de Tratamento de Esgoto, criando dois cenários de exploração do empreendimento.

\section{MATERIAL E MÉTODOS}

A análise da viabilidade econômico-financeira foi realizada a partir da estimativa de funcionamento de uma Estação de Tratamento de Esgoto, com uso de reatores anaeróbicos e capacidade média de tratamento diário de $3.356 \mathrm{~m}^{3}$ de esgoto. Na caracterização da Estação de Tratamento de Esgoto foram propostos dois diferentes cenários dentro da temática do tratamento de esgoto e destinação do lodo gerado. Os cenários foram: ETE I - Estação de Tratamento de Esgoto que destina todos os resíduos sólidos produzidos para o aterro sanitário e ETE II - Estação de Tratamento de Esgoto que beneficia o lodo de esgoto gerado, por meio do processo de compostagem para a produção de adubo destinado à produção de mudas de reflorestamento, destinando demais resíduos sólidos produzidos ao aterro sanitário.

Foram levantadas todas as receitas (recebimento da taxa de esgoto e/ou venda do composto orgânico tratado) e despesas (aquisição da área, construção de benfeitorias, aquisição de máquinas, equipamentos, ferramentas e veículos, construção de cercas, pagamentos de mão de obra contratada, pagamento de encargos trabalhistas, custos com destinação do lodo ao aterro e/ou tratamento do lodo de esgoto e comercialização, custos com reparo e manutenção, pagamento de tributos e licenças ambientais, pagamento de água, luz, e telefone, custos com serviços administrativos, entre outros) envolvidas na implantação e exploração da Estação de Tratamento de Esgoto.

A partir do levantamento das informações e dos dados financeiros durante um ano, projetaram-se os cenários para um horizonte de cinco anos de exploração do empreendimento. Os dois cenários analisados foram diferenciados de acordo com a destinação dos resíduos sólidos gerados nas Estações e refletindo a realidade do empreendimento, bem como a adequação à legislação ambiental vigente. 
No primeiro cenário, caracterizou-se a ETE I de acordo com o que se executa atualmente, com a destinação dos resíduos sólidos produzidos para o aterro sanitário com todos os custos de produção envolvidos. Para o segundo cenário, considerou-se na caracterização da ETE II a utilização do lodo de esgoto para a produção de mudas de reflorestamento, a partir da produção de adubo orgânico, pelo processo de compostagem.

Para cada cenário avaliado foi construído um fluxo de caixa que retratou a caracterização da proposta, a partir das informações levantadas e computadas em planilhas do MS-Excel ${ }^{\circledR}$ (Microsoft Corp., Redmond, WA, EUA), mensalmente, considerando todos os itens de produção necessários para a implantação e exploração da Estação de Tratamento de Esgoto, em um horizonte temporal de cinco anos. Para o cenário ETE II foi considerada que a caracterização do lodo de esgoto foi realizada semestralmente, incluindo os seguintes parâmetros: potencial agronômico, substâncias inorgânicas e orgânicas potencialmente tóxicas, indicadores bacteriológicos e agentes patogênicos, e estabilidade, de acordo com o que preconiza a Resolução CONAMA 375, de 29 de agosto de 2006 (BRASIL, 2006). Foram realizadas as cotações dos preços praticados no mercado local de todos os itens envolvidos na construção e operação dos cenários entre janeiro e dezembro de 2013, período este em que foi realizado o estudo, permitindo assim descrever o cenário real na localidade de realização do estudo. Após a cotação, os preços foram corrigidos monetariamente, aplicando-se o Índice Geral de Preços - Disponibilidade Interna (IGP-DI) da Fundação Getúlio Vargas (FGV, 2017), atualizando-os para dezembro de 2016 (mês de referência).

Com base nos fluxos de caixa foram obtidas as receitas e as despesas, mensalmente, determinando-se o fluxo líquido mensal. Sobre os fluxos de caixa foram aplicadas diferentes taxas de desconto de 10, 20, 40 e 60\% ao ano para que o capital financeiro envolvido sofresse desvalorização monetária. Com base nesses dados, determinaram-se os indicadores econômicos de rentabilidade: Valor Presente Líquido (VPL) e Taxa Interna de Retorno (TIR).

O método do Valor Presente Líquido (VPL) tem como finalidade valorar em termos de valor presente o impacto dos eventos futuros associados a um projeto ou alternativa de investimento, ou seja, mede o valor presente dos fluxos de caixa 
gerados pelo projeto ao longo de sua vida útil (SAMANEZ, 2002). É igual à soma dos valores presentes de todas as entradas e saídas futuras de caixa, descontando-se uma taxa de juros que corresponde à taxa mínima de atratividade. Essa taxa representa o retorno que a atividade poderia obter em uma aplicação no mercado (CONTADOR, 1988). A expressão utilizada para determinação do VPL é:

$$
V P L=\sum_{t=1}^{n} \frac{F C_{t}}{(1+i)^{t}}
$$

Onde:

$\mathrm{VPL}=$ valor presente líquido;

$\mathrm{FC}=$ valor do fluxo líquido no período $\mathrm{t}$;

$\mathrm{n}=$ número de fluxos;

$\mathrm{i}=$ taxa de juros;

$\mathrm{t}=$ período de análise $(\mathrm{t}=1,2,3 \ldots \mathrm{n})$.

Por definição, a Taxa Interna de Retorno é a taxa de retorno esperada do projeto de investimento. $\mathrm{O}$ método da TIR não tem como finalidade a avaliação da rentabilidade absoluta a um determinado custo de capital, como o VPL, mas ao contrário, seu objetivo é encontrar uma taxa intrínseca de rendimento (SAMANEZ, 2002). Contador (1988) define a taxa interna de retorno (TIR) como sendo a taxa de juros que iguala a zero o VPL de um projeto, ou seja, é a taxa de desconto que iguala o valor presente dos benefícios de um projeto ao valor presente dos seus custos. A TIR é calculada pela expressão:

$$
0=F C_{0}+\frac{F C_{1}}{(1+T I R)^{1}}+\frac{F C_{2}}{(1+T I R)^{2}} \frac{F C_{3}}{(1+T I R)^{3}}+\cdots+\frac{F C_{n}}{(1+T I R)^{n}}
$$

Onde:

$\mathrm{FC}_{\mathrm{n}}=$ fluxo de caixa no período $\mathrm{n} ;$

TIR = taxa interna de retorno;

$\mathrm{n}=$ prazo 
A taxa mínima de atratividade (TMA) escolhida para análise dos resultados obtidos neste modelo de investimento foi a taxa Selic, que variou entre 7,1 e 9,9\% ao ano (BCB, 2018), durante o período compreendido entre janeiro e dezembro de 2013.

Considerando um horizonte de cinco anos de exploração das diferentes estações de tratamento de esgoto doméstico foi determinado o tempo de recuperação do capital investido (payback) que indicou o tempo necessário para o lucro acumulado gerado igualar ao investimento inicial, demonstrado em unidades de tempo (URTADO et al., 2009). Para calculá-lo foi necessário obter o fluxo de caixa livre acumulado, considerando o somatório de todos os fluxos de caixa da sua implantação e exploração no horizonte avaliado.

O fluxo de caixa que levou em consideração a aplicação de taxas de desconto foi determinado o tempo de recuperação do capital investido, sendo denominado de payback descontado. Normalmente, os primeiros meses são negativos e depois, com o acúmulo do resultado positivo operacional, esse valor torna-se definitivamente positivo.

Posteriormente, realizou-se a análise de sensibilidade (MELO; REIS; GORESTIN, 1999) para identificar os principais itens de produção que interferiram nos resultados econômico-financeiros de cada cenário avaliado, diante das oscilações de preços ocorridas no mercado. Em cada fluxo de caixa, procedeu-se uma variação de $10 \%$, sempre no sentido desfavorável, para cada item relacionado nas receitas ou nas despesas, considerando um aumento no preço quando se tratava de despesas e uma diminuição no preço quando se tratava de receitas.

Após a identificação dos itens de maior impacto econômico-financeiro em cada cenário, procedeu-se a realização da análise de risco financeiro, utilizando o método de Monte Carlo (BLANK; TARQUIN, 2008). Nesta análise, determinou-se a probabilidade de insucesso de cada cenário, quando submetido às diferentes taxas de desconto (10, 20, 40 e 60\% ao ano). Adotou-se a metodologia da distribuição triangular proposta por Bressan (2002), que considerou o preço mais provável, o preço mínimo e o preço máximo, determinados a partir do levantamento realizado nos preços de cada item durante o período de um ano, para verificar a oscilação de preços praticada no mercado. 
Foram simulados 50.000 fluxos de caixa para cada cenário, considerando os dez itens de produção mais relevantes identificados na análise de sensibilidade que foram considerados como variáveis aleatórias, permitindo analisar o efeito de diversos cenários econômicos (MELO; REIS; GORESTIN, 1999), sendo aqueles de menor impacto econômico considerados como valores determinísticos.

\section{RESULTADOS E DISCUSSÃO}

Os dois cenários estudados apresentaram viabilidade econômico-financeira quando submetidos à taxa de desconto de $40 \%$ ao ano por apresentarem VPLs positivos (Tabela 1).

Tabela 1. Valor Presente Líquido (VPL), em reais, submetido às diferentes taxas anuais de desconto e Taxa Interna de Retorno (TIR), em \%

\begin{tabular}{cccccc}
\hline \multirow{2}{*}{ Cenário } & \multicolumn{5}{c}{ Taxa de desconto } \\
\cline { 2 - 6 } & $10 \%$ & $20 \%$ & $40 \%$ & $60 \%$ & TIR \\
\hline \multirow{2}{*}{ ETE I } & $2.406 .405,98$ & $1.537 .097,30$ & $517.342,94$ & $-30.740,76$ & 58,5 \\
ETE II & $2.764 .000,52$ & $1.794 .028,26$ & $652.371,42$ & $36.375,50$ & 61,6 \\
\hline
\end{tabular}

ETE I - Estação de Tratamento de Esgoto que destina todos os resíduos sólidos produzidos para o aterro sanitário. ETE II - Estação de Tratamento de Esgoto que beneficia o lodo de esgoto gerado, por meio do processo de compostagem.

Considerando que o capital financeiro imobilizado na construção e exploração da Estação de Tratamento de Esgoto foi submetido a uma desvalorização em $10 \%$ ao ano, para um horizonte de cinco anos de exploração, comparar os resultados obtidos para o empreendimento com a taxa Selic, taxa esta utilizada em financiamentos diários, indica ser uma boa opção de análise da imobilização do capital financeiro nesse modelo de investimento. Ambos cenários analisados apresentaram TIR superior a TMA escolhida, o que indicou serem boas opções de investimento no mercado.

A ETE II foi a que apresentou a TIR mais atrativa para investimento, com remuneração anual do capital investido na ordem de 61,6\% (Tabela 1), o que de- 
monstrou que além do investidor obter maior remuneração do capital financeiro investido, esta proposta ainda proporcionou condições de adequação do empreendimento à legislação ambiental, com a redução dos impactos ambientais gerados, uma vez que na Estação de Tratamento de Esgoto se realiza o tratamento do lodo de esgoto produzido e se dá o destino correto desse resíduo sólido, estando a atividade desenvolvida na Estação adequada ambientalmente.

O elevado rendimento econômico-financeiro observado para a ETE II foi devido à destinação adequada do principal resíduo sólido produzido, o lodo de esgoto, que apresentou alto custo de produção, quando sua deposição foi realizada em aterro sanitário. Uma vez realizada a compostagem na própria Estação de Tratamento de Esgoto, os custos inerentes ao processo foram inferiores àqueles praticados com o transporte e destinação em aterro sanitário, melhorando assim a rentabilidade econômico-financeira da ETE II, além de minimizar o impacto ambiental gerado pela atividade.

Analisando os cenários propostos, pode-se notar que a partir do uso da taxa de desconto de $10 \%$ ao ano sobre os fluxos de caixa das Estações de Tratamento de Esgoto, os VPLs foram positivos para os cenários projetados para a ETE I e ETE II. A exploração da atividade quando realizada dentro das normas técnicas, respeitando a legislação ambiental vigente, pode promover bons rendimentos financeiros para 0 investidor e, ainda, evitar que processos judiciais e multas ambientais sejam aplicados por estarem atuando fora da regulamentação proposta por órgãos ambientais.

O tempo de recuperação do capital investido (payback descontado), necessário para o investimento na estação de tratamento de esgoto doméstico, ocorreu no curto prazo para a ETE I, com dois anos e três meses, e para ETE II, com dois anos e dois meses, sendo este tempo considerado um período de curto prazo.

Por meio da análise de sensibilidade foi possível identificar o impacto econômico-financeiro dos dez principais itens envolvidos na implantação e exploração da Estação de Tratamento de Esgoto (Tabela 2). O recebimento da taxa de esgoto foi o item de maior impacto econômico-financeiro observado nos cenários estudados para cada estação de tratamento de esgoto doméstico. A queda na arrecadação deste tributo por conta dos serviços prestados pode levar a proposta a se inviabilizar financeiramente. 
Tabela 2. Resultado da análise de sensibilidade, indicando os principais itens de maior impacto econômico nos resultados obtidos para o VPL, quando se considerou uma variação em $10 \%$ nos preços

\begin{tabular}{lll}
\hline Cenários & \multicolumn{1}{c}{ Categoria } & Variação do VPL \\
\hline \multirow{2}{*}{ Recebimento da taxa de esgoto } & $-\mathrm{R} \$ 636.795,10$ \\
& Preço de compra do reator & $-\mathrm{R} \$ 123.704,21$ \\
& Custo na destinação do lodo de esgoto & $-\mathrm{R} \$ 68.813,98$ \\
& Custo com a construção do leito de secagem & $-\mathrm{R} \$ 33.754,11$ \\
$\quad$ Custo na destinação dos resíduos da caixa de gordura & $-\mathrm{R} \$ 18.272,92$ \\
& Despesas com energia elétrica & $-\mathrm{R} \$ 17.721,90$ \\
& Despesas com reparo e manutenção da ETE & $-\mathrm{R} \$ 17.481,10$ \\
& Destinação dos resíduos sólidos & $-\mathrm{R} \$ 17.130,87$ \\
& Custo de mão de obra com responsável técnico & $-\mathrm{R} \$ 17.130,87$ \\
& Preço de compra do terreno & $-\mathrm{R} \$ 13.594,86$ \\
\hline Recebimento da taxa de esgoto & $-\mathrm{R} \$ 636.795,10$ \\
Preço de compra do reator & $-\mathrm{R} \$ 123.704,21$ \\
Custo com a construção do leito de secagem & $-\mathrm{R} \$ 33.754,11$ \\
Destinação dos resíduos da caixa de gordura & $-\mathrm{R} \$ 18.272,92$ \\
Despesas com energia elétrica & $-\mathrm{R} \$ 17.721,90$ \\
Despesas com reparo e manutenção da ETE & $-\mathrm{R} \$ 17.481,10$ \\
Custo de mão de obra com responsável técnico & $-\mathrm{R} \$ 17.130,86$ \\
Custo com a destinação de resíduos sólidos & $-\mathrm{R} \$ 17.130,86$ \\
Custo com a construção da composteira & $-\mathrm{R} \$ 16.713,95$ \\
Custo de mão de obra com auxiliar de serviços gerais & $-\mathrm{R} \$ 15.417,78$ \\
\hline
\end{tabular}

No cenário em que foi considerada a destinação dos resíduos sólidos produzidos para o aterro sanitário (ETE I), observou-se que o item que mais influenciou negativamente o VPL, após o recebimento da taxa de esgoto, foi o valor do capital financeiro imobilizado com a compra do reator, seguido dos custos inerentes a destinação do lodo de esgoto produzido pela ETE no aterro sanitário.

Estes resultados demonstraram o alto custo de produção envolvido no transporte e destinação desses resíduos e o tratamento adequado destes pode reduzir as despesas no fluxo de caixa, melhorando a rentabilidade econômico-financeira 
do empreendimento, além de que o aumento no pagamento destes custos por parte da empresa gestora do aterro sanitário pode refletir em perdas econômicas na gestão financeira da Estação de Tratamento de Esgoto.

Na ETE II, a adoção da compostagem não foi observada influência dos custos inerentes a destinação do lodo de esgoto, ou seja, esse resíduo sólido quando tratado adequadamente e sua destinação se dá de forma correta e dentro da regulamentação ambiental, este item não promove alteração negativa nos resultados do valor presente líquido obtido. Neste cenário observou-se que além do valor recebido pela taxa de esgoto e a compra do reator, itens estes que também influenciaram a ETE I, o investimento na construção do leito de secagem foi um item de extrema relevância e influência sobre os resultados do VPL. Por se tratar de uma benfeitoria, a imobilização de capital financeiro nesta estrutura tende a valorizar o valor patrimonial da ETE II.

O risco econômico-financeiro de investimentos em estações de tratamento de esgoto doméstico que tratam dos resíduos sólidos produzidos por meio da compostagem ou promovem a destinação destes aos aterros sanitários de forma adequada foi considerado baixo (Tabela 3).

Tabela 3. Resultado da análise de risco: probabilidade dos cenários apresentarem VPL negativo, considerando diferentes taxas anuais de desconto

\begin{tabular}{|c|c|c|c|c|}
\hline \multirow{2}{*}{ Cenários } & \multicolumn{4}{|c|}{ Taxa de desconto } \\
\cline { 2 - 5 } & $10 \%$ & $20 \%$ & $40 \%$ & $60 \%$ \\
\hline ETE I & $0,00 \%$ & $0,00 \%$ & $0,12 \%$ & $73,59 \%$ \\
\hline ETE II & $0,00 \%$ & $0,00 \%$ & $0,01 \%$ & $56,07 \%$ \\
\hline
\end{tabular}

ETE I - Estação de Tratamento de Esgoto que destina todos os resíduos sólidos produzidos para o aterro sanitário. ETE II - Estação de Tratamento de Esgoto que beneficia o lodo de esgoto gerado, por meio do processo de compostagem.

O método de Monte Carlo é, dentre os métodos que utilizam a probabilidade na análise dos riscos, o mais simples do ponto de vista prático, além de apresentar custo razoavelmente baixo (NORONHA, 1987). O princípio básico do processo de simulação reside no fato de que a frequência relativa de ocorrência do acontecimento de certo fenômeno tende a aproximar-se da probabilidade matemática de ocorrência desse mesmo fenômeno, quando a experiência é repetida um grande número de 
vezes e assume valores aleatórios dentro dos limites estabelecidos (HERTZ, 1964). Ao estabelecer os preços mínimos, médios e máximos de cada item componente do sistema de tratamento de esgoto foi possível observar a importância do método na determinação do risco da proposta estudada e analisar a importância da adoção ou não da tecnologia no contexto ambiental, promovendo o tratamento do esgoto doméstico gerado, de acordo com a legislação ambiental vigente e respeitando o meio ambiente.

$\mathrm{Na}$ determinação do risco econômico-financeiro do investimento na ETE que trata o lodo de esgoto doméstico foi considerada a realização semestral de análises de composição físico-química, garantindo que o produto tratado e comercializado atendeu aos padrões da legislação vigente. Em condições de resultados laboratoriais que inviabilizassem o uso do lodo de esgoto doméstico tratado para produção de mudas de reflorestamento, a ETE teria seus custos de produção aumentados por necessitar dar a destinação desse resíduo ao aterro sanitário. Por apresentar uma rentabilidade elevada (61,6\% ao ano), a ETE II não teria sua atividade inviabilizada financeiramente, quando a destinação do lodo de esgoto doméstico ocorresse no aterro sanitário.

\section{CONSIDERAÇÕES FINAIS}

Por apresentarem valor presente líquido positivo a uma taxa de desconto de $10 \%$ ao ano, os cenários avaliados para cada estação de tratamento de esgoto foram viáveis financeiramente.

A estação de tratamento que promove a destinação do lodo de esgoto por meio da compostagem foi a mais atrativa para investimento por proporcionar maior rentabilidade financeira, considerando a produção de lodo de esgoto Classe A e sem contaminantes orgânicos e inorgânicos que inviabilizem a sua reciclagem agrícola.

A recuperação do capital financeiro investido na construção e exploração de estação de tratamento de esgoto ocorre no curto prazo.

$\mathrm{O}$ item de maior impacto financeiro que pode influenciar na proposta de investimento é o valor cobrado para a taxa de esgoto. 
O risco financeiro do investimento em estações de tratamento de esgoto doméstico que tratam o resíduo sólido por meio da compostagem ou promovem a sua destinação a aterros sanitários é considerado baixo.

\section{REFERÊNCIAS}

BANCO CENTRAL DO BRASIL. Taxa Selic. Disponível em: http://www.bcb.gov.br/ pt-br/\#!/n/SELICTAXA. Acesso em: 23 jan. 2018.

BETTIOL, W.; CAMARGO, O. A. de. Lodo de Esgoto: Impactos Ambientais na Agricultura. Jaguariúna: Embrapa Meio Ambiente, 2006, 349p.

BLANK, L.; TARQUIN, A. Engenharia econômica. 6. ed. São Paulo: McGraw-Hill, 2008. .

BRASIL. Resolução CONAMA no 375, de 29 de agosto de 2006. Define critérios e procedimentos, para o uso agrícola de lodos de esgoto gerados em estações de tratamento de esgoto sanitário e seus produtos derivados, e dá outras providências. Diário Oficial [da] República Federativa do Brasil, Brasília, 30 ago. 2006.

BRESSAN, G. Modelagem e simulação de sistemas computacionais: abordagem sistemática de modelagem e análise de desempenho de sistemas. São Paulo: LarcPCS/Epusp, 2002.

CONTADOR, C. R. Avaliação Social de Projetos. 2. ed. São Paulo: Editora Atlas, 1988.

DORES-SILVA, P. R.; LANDGRAF, M. D.; REZENDE, M. O. de O. Processo de estabilização de resíduos orgânicos: vermicompostagem versus compostagem. Química Nova, São Paulo, v. 36, n. 5, p. 640-645, mai. 2013.

FUNDAÇÃO GETÚLIO VARGAS - FGV. Índice geral de preços: disponibilidade interna. Revisão atualizada diariamente. Disponível em: http://www.antigofgvdados. fgv.br. Acesso em: 30 jan. 2017. 
GOMES, D. R.; CALDEIRA, M. V. W.; DELARMELINA, W. M.; GONÇALVES, E. de O.; TRAZZI, P. A. Lodo de esgoto como substrato para produção de mudas de Tectona grandis L. Cerne, Lavras, v. 19, n. 1, p. 123-131, jan./mar. 2013.

HERTZ, D. B. Risk analysis in capital investment. Harvard Business Review, New York, v. 42, n. 1, p. 95-106, jan./fev. 1964.

LEMAINSKI, J.; SILVA, J. E. da. Avaliação agronômica e econômica da aplicação de biossólido na produção de soja. Pesquisa Agropecuária Brasileira, Brasília, v. 41, n. 10 , p. $1477-1484$, out. 2006.

LOBO, T. F.; GRASSI FILHO, H.; BÜLL, L. T.; SOUZA, F. L. P. Efeito do nitrogênio e do lodo de esgoto na nutrição do feijoeiro. Revista Verde de Agroecologia e Desenvolvimento Sustentável, Pombal, v. 10, n. 2, p. 33-41, abr.jun. 2015.

LOBO, T. F.; GRASSI FILHO, H.; BULL, L. T.; KUMMER, A. C. B. Efeito do lodo de esgoto e do nitrogênio nos fatores produtivos do girassol. Revista Brasileira de Engenharia Agrícola e Ambiental, Campina Grande, v. 17, n. 5, p. 504-509, mai. 2013.

LOBO, T. F.; GRASSI FILHO, H.; BULL, L. T. Efeito do nitrogênio e do lodo de esgoto nos fatores produtivos do feijoeiro. Revista Ceres, Viçosa, v. 59, n. 1, p. 118-124, jan./fev. 2012.

LOPES, M. A.; CARVALHO, F. M. Custo de produção e análise de rentabilidade na pecuária leiteira. In: SIMPÓSIO GOIANO SOBRE MANEJO E NUTRIÇÃO DE BOVINOS, 3., 2001, Goiânia. Anais [...]. Goiânia: CBNA, 2001. p. 243-278.

MELO, A. C. G.; REIS, M. S.; GORESTIN, B. G. Análise financeira de projetos de investimento sob enfoque de incertezas. In: SEMINÁRIO NACIONAL DE PRODUÇÃO E TRANSMISSÃO DE ENERGIA ELÉTRICA, 1., 1999, Foz do Iguaçu. Anais [...]. Foz de Iguaçu: SNPTEE, 1999. 6p.

NORONHA, J. F. Projetos agropecuários: administração financeira, orçamento e viabilidade econômica. 2. ed. São Paulo: Atlas, 1987.

OLIVEIRA, D. Q. L. de; CARVALHO, K. T. G.; BASTOS, A. R. R.; OlIVEIRA, L. C. A. 
de; MARQUES, J. J. G. de S. e M.; NASCIMENTO, R. S. de M. P. do. Utilização de resíduos da indústria de couro como fonte nitrogenada para o capim-elefante. Revista Brasileira de Ciência do Solo, Viçosa, v. 32, n. 1, p. 417-424, jan./fev. 2008.

QUINTANA, N. R. G.; CARMO, M. S. do; MELO, W. J. de. Custo de produção do milho de verão adubado com lodo de esgoto. In: CONGRESSSO DA SOCIEDADE BRASILEIRA DE ECONOMIA, ADMINISTRAÇÃO E SOCIOLOGIA RURAL, 46., 2008, Rio Branco. Anais [...]. Rio Branco: SOBER, 2008. 9p.

SAMANEZ, C. P. Matemática financeira: aplicações à análise de investimentos. 3. ed. São Paulo: Prentice Hall, 2005.

SANTOS, F. E. V.; KUNZ, S. H.; CALDEIRA, M. V. W.; AZEVEDO, C. H. S.; RANGEL, O. J. P. Características químicas de substratos formulados com lodo de esgoto para produção de mudas florestais. Revista Brasileira de Engenharia Agrícola e Ambiental, Campina Grande, v. 18, n. 9, p. 971-979, set. 2014.

SILVA, F. C. da; BOARETTO, A. E.; BERTON, R. S.; ZOTELLI, H. B.; PEXE, C. A.; BERNARDES, E. M. Efeito de lodo de esgoto na fertilidade de um Argissolo VermelhoAmarelo cultivado com cana-de-açúcar. Pesquisa Agropecuária Brasileira, Brasília, v. 36, n. 5, p. 831-840, mai. 2001.

TRIGUEIRO, R. M.; GUERRINI, I. A. Utilização de lodo de esgoto na produção de mudas de aroeira-pimenteira. Revista Árvore, Viçosa, v. 38, n. 4, p. 657-665, jul./ ago. 2014.

URTADO, E. S.; SANTO, V. da S.; QUINTAIROS, P. C. R.; OLIVEIRA, E. A. de A. Q. Aplicação do método do valor presente líquido (VPL) na análise da viabilidade econômica de projetos na indústria metal mecânica: um estudo de caso. In: ENCONTRO LATINO AMERICANO DE PÓS-GRADUAÇÃO, 9., 2009, São José dos Campos. Anais [...]. São José dos Campos: UNIVAP, 2009. p. 1-4. Disponível em: http://www.inicepg.univap.br/cd/INIC_2009/anais/arquivos/0732_0960_01.pdf. Acesso em: 09 mar. 2017. 